\title{
Doctor of Science
}

National Cancer Institute

\section{Source}

National Cancer Institute. Doctor of Science. NCI Thesaurus. Code C71379.

A doctoral deg ree earned with the approval of a committee on the basis of original research and publications. It is awarded predominantly in doctoral level science programs such as engineering, information systems, medical and health sciences, and health economics. 